\title{
Performance of Italian zeolitic tuffs and pozzolana in 2-chlorophenol removal from contaminated groundwater: the lab-scale experience
}

\author{
M. R. Boni, S. Sbaffoni \& L. Tuccinardi \\ Department of Hydraulics, Transportation and Roads, \\ "SAPIENZA" University of Rome, Italy
}

\begin{abstract}
The physical and chemical properties of zeolites and the availability of localized deposits of naturally occurring zeolitized tuffs and pozzolana, make them desirable for and applicable to the remediation of contaminated groundwater. This paper documents the results of a laboratory study to test the capacity of native Italian zeolites to remove 2-chlorophenol (2-CP) from water. Italian zeolitic tuff and pozzolana were characterized in terms of their chemical and structural properties and of their adsorption capacities. Moreover, the experimental activity investigated their adsorption behaviour: time and $\mathrm{pH}$ dependence of the adsorption process was evaluated. The results of the time-dependence adsorption study under a constantly stirred condition showed that the adsorption increases with a longer contact time for all samples; the highest adsorption occurred at $\mathrm{pH}=8 \div 8.5$. Due to the good removal efficiencies obtained, a column test simulating the condition of an in situ permeable reactive barrier was carried out, in order to estimate the removal kinetics and the long-term behaviour. The removal efficiencies reached values higher than $90 \%$, even if some long-term performance worsening occurred, due to the progressive exhaustion of the adsorption sites. These experiments demonstrate the capacity of naturally occurring zeolites to remove 2-CP from water and the opportunity to make economic use of these native deposits for in situ groundwater remediation.

Keywords: natural zeolites, 2-chlorophenol, permeable reactive barriers, tuff, pozzolana, groundwater.
\end{abstract}




\section{Introduction}

Chlorophenols are induced into the environment in the waste stream of several industrial operations through their use as biocides or disinfectants or as a by-product of other industrial operations; they can also appear as degradation products of other chlorinated xenobiotics [1]. Because of their toxic effects, the accumulation of chlorophenols in soil and groundwater is of concern. Several decontamination techniques are available for the removal of contaminants from water; biodegradation is a technique that could potentially degrade these contaminants to innocuous products [2,3]. However, the majority of experiments have been conducted only under laboratory conditions and scaling-up biodegradation to field conditions is not a simple process. Applying chemical technologies for the degradation of chlorophenols may be more suitable. Of all approaches, adsorption by activated carbon appears to be most prominent [4]. As activated carbon is relatively costly, attempts have been made to utilize lower-cost and naturally present materials $[5,6]$. Among these, natural zeolites, which are abundantly present in Italy in tuff and pozzolana deposits, can be potentially used as adsorbent for phenol and its derivatives $[7,8]$. They are rich in chabazite and phillipsite and their physical and chemical properties make them suitable for wide applications, including the removal of pollutants from the environment. Nevertheless, few attempts have been made for taking advantage of this ability of zeolites in the case of organic pollutants.

The present work aims at widening the applications of the local materials, including their possible use in the in situ removal of chlorophenols from groundwater. In the experimental activity presented here the performance of the Italian native zeolitic tuff and pozzolana in 2-chlorophenol (2-CP) removal from contaminated groundwater was checked.

Both batch and column tests were carried out. The batch tests aimed at defining the influence of $\mathrm{pH}$ and time on the adsorption process. The results obtained during the column tests, simulating an in situ permeable reactive barrier, allowed estimation of the 2-CP removal kinetic.

\section{Materials and methods}

\subsection{Materials}

Tuff and pozzolana were collected at two caves near Rome; they were characterized in terms of natural $\mathrm{pH}$ (equal to 9.3 and 9.43 , respectively), unit dry weight (equal to 0.96 and $1.26 \mathrm{~g} / \mathrm{cm}^{3}$, respectively), mechanical characteristics and grain size distribution. In the present experimental study only the fraction between 1 and $4 \mathrm{~mm}$ was used.

Additionally, the materials were analyzed by X-Ray Diffractometry, confirming the abundance of the natural zeolites chabazite and phillipsite. Both materials were characterized in terms of their environmental quality through leaching tests [9]. Tuff and pozzolana exhibited composition and contaminants release fully compatible with their use for in situ groundwater remediation. 


\subsection{Experimental apparatus: batch test}

The experimental activity was scheduled as follows:

- $\quad$ Batch tests: to evaluate $\mathrm{pH}$ - and time-dependence of the adsorption process.

- Column tests: to check the long-term behaviour of the reactive media and to calculate the removal kinetics.

\subsubsection{Batch tests}

The batch tests were performed in a continuously mixing jar-tester at a liquid-tosolid ratio (L/S) equal to $101 / \mathrm{kg}$ for $4,8,24,30$ and 48 hours; the $\mathrm{pH}$ values investigated were those acceptable for groundwater, in the range 7-9.

Additionally, the effect of possible activation through urea and thiourea on tuff was checked. A $1.18 \mathrm{M}$ thiourea solution and $1.67 \mathrm{M}$ urea solution were mixed with tuff at a L/S equal to $50 \mathrm{l} / \mathrm{kg}$ for $48 \mathrm{~h}$ at temperatures between 50 and $60^{\circ} \mathrm{C}$ [7], in order to avoid damages or alteration of the zeolitic structure. At the end of the activation procedure, tuff was washed and then maintained in an oven at $50^{\circ} \mathrm{C}$ for 12 hours. The adsorption tests on activated tuff were performed at a natural $\mathrm{pH}$ with a $\mathrm{L} / \mathrm{S}=10 \mathrm{l} / \mathrm{kg}$.

In all the tests, a $12.6 \mathrm{mg} / \mathrm{l}$ initial 2-CP concentration was used. The eluates obtained were characterized in terms of total phenolic compounds and 2-CP content through a spectrophotometer [10] and GC-MS, respectively.

\subsubsection{Column tests}

The column tests were carried out introducing zeolitic tuff and pozzolana in separate Perspex cylinders, having a height equal to $100 \mathrm{~cm}$ and internal diameter equal to $5 \mathrm{~cm}$. The reactors were equipped with sampling ports for the collection of samples to be analyzed at $5 \mathrm{~cm}$ (port 1), $20 \mathrm{~cm}$ (port 2), $40 \mathrm{~cm}$ (port 3) and $80 \mathrm{~cm}$ (port 4) from the bottom. Each sampling port was equipped with gastight and watertight fittings (fig. 1). Sampling was made daily using Luer-Lock syringes. Samples were immediately introduced into glass vials and analysed. All tubing and connections were of VitonTM.

Prior to beginning the experimental activity with 2-CP, each column was saturated using DDW; in order to achieve a good saturation, about six pore volumes (PVs) of DDW were fed upwards to the column. The 2-CP solution was placed in a Tedlar bag (SKC) to prevent headspace as the bag empties out and it was fed upwards to the column through a multichannel peristaltic pump (ISMATEC IP, $\pm 0.005 \mathrm{~cm}^{3} / \mathrm{min}$ precision). The outlet was collected in a HDPE bottle. All the results presented here relate to samples collected after five PVs were run in the column in order to reach a steady-state condition.

Four different columns were studied; their hydraulic and operational characteristics are shown in table 1.

\section{Results and discussion}

\subsection{Batch tests}

As shown in fig. 2a, 2-CP removal efficiency increased over time at a longer contact time, even if in some cases no significant differences were observed 
between 30 and 48 hours; probably 30 hours were sufficient to reach the equilibrium conditions in the system. As far as $\mathrm{pH}$ is concerned, the worst performances were observed at $\mathrm{pH}=9.5$ for both pozzolana and tuff, with final removal efficiencies lower than 50\%. The best performances occurred in correspondence to slightly alkaline $\mathrm{pH}$, with removal equal to about $65 \%$ for both materials.

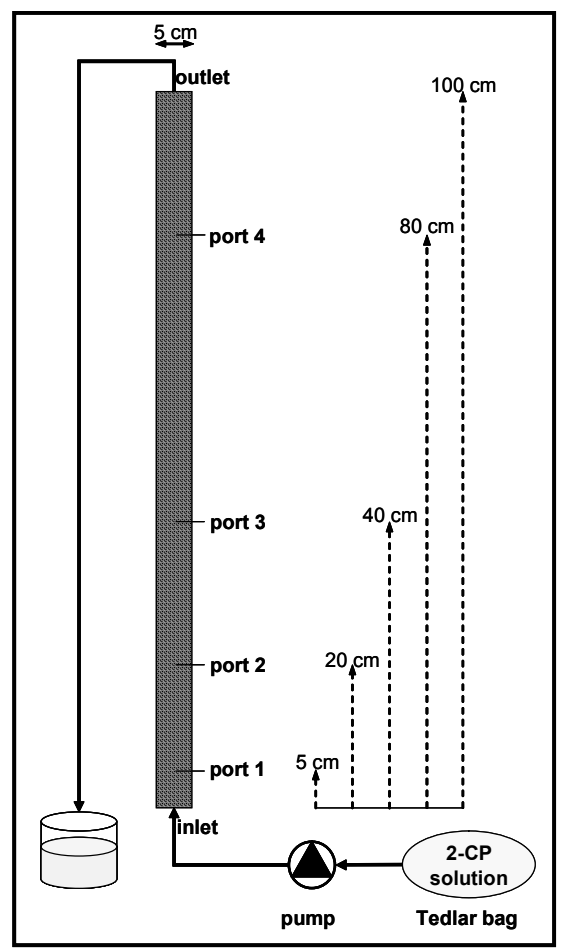

Figure 1: Scheme of the column reactor.

Table 1: Hydraulic and operational characteristics of the columns.

\begin{tabular}{|l|c|c|c|c|c|c|c|}
\hline column & $\begin{array}{c}\text { reactive } \\
\text { medium }\end{array}$ & $\begin{array}{c}2-\mathrm{CP} \text { in } \\
\text { the inlet } \\
(\mathrm{mg} / \mathrm{l})\end{array}$ & $\begin{array}{c}\text { material } \\
\text { weight } \\
(\mathrm{kg})\end{array}$ & $\begin{array}{c}\mathrm{PV} \\
(\mathrm{ml})\end{array}$ & $\begin{array}{c}\text { flow rate } \\
(\mathrm{ml} / \mathrm{min})\end{array}$ & $\begin{array}{c}\text { hydraulic } \\
\text { retention time } \\
\text { of 1 PV }(\mathrm{h})\end{array}$ & $\begin{array}{c}\text { velocity } \\
(\mathrm{m} / \mathrm{d})\end{array}$ \\
\hline P1 & pozzolana & 12.6 & 1.98 & 679 & 0.5 & 23 & 1.06 \\
\hline T1 & tuff & 12.6 & 1.56 & 809 & 0.5 & 27 & 0.85 \\
\hline P2 & pozzolana & 37 & 1.96 & 1129 & 0.5 & 38 & 0.64 \\
\hline T2 & tuff & 37 & 1.86 & 1129 & 0.5 & 38 & 0.64 \\
\hline
\end{tabular}

During the tests with activated tuff, $\mathrm{pH}$ was periodically measured: the values detected in the batch with activated and not activated tuff were very similar during the entire period (48 h), remaining in the range 9-9.5. The results of such tests in terms of 2-CP removal efficiency are presented in fig. $2 b$. No increase in 
the efficiency occurred in the case of activation by urea. On the contrary, thiourea seemed to improve tuff performance; in fact, after $48 \mathrm{~h}$, the removal efficiency of the activated tuff was equal to $20 \%$ (about $5 \%$ higher than tuff).

Nevertheless, the removal increase was considered insufficient to justify the additional costs and the operational burdens linked to the activation procedure in a real-scale application. Consequently, the experimental activity continued only on natural tuff and pozzolana as reactive media in the column tests.
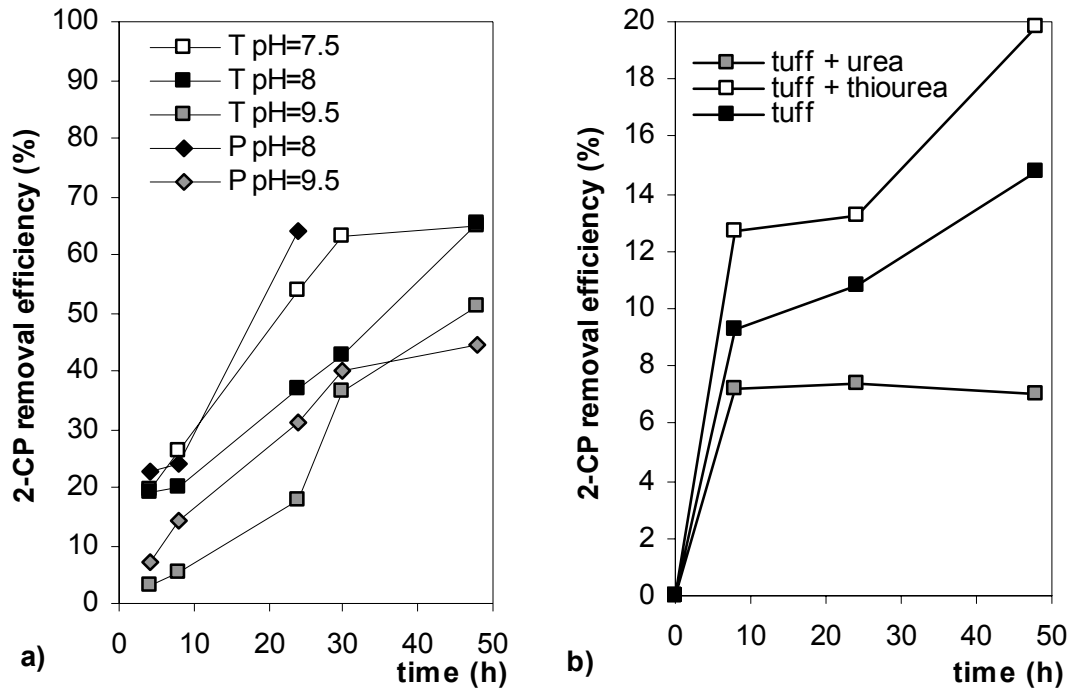

Figure 2: $\quad$ Results of the batch tests $(\mathrm{T}=$ tuff; $\mathrm{P}=$ pozzolana): time and $\mathrm{pH}$ dependence (a) and influence of tuff activation (b).

\subsection{Column test}

The $\mathrm{pH}$ and 2-CP concentrations were measured in the samples collected daily in correspondence to each sampling port of the columns during the entire experimental activity. In fig. 3 the removal efficiency obtained in the outlet of the columns T1 and P1 (initial 2-CP concentration equal to $12.6 \mathrm{mg} / \mathrm{l}$ ) are shown. In the former, the 2-CP concentrations were quite high in the outlet until day 10 , with removal efficiencies lower than $25 \%$. After day 11 the performance of the system improved, with concentrations in the outlet ranging between 0.15 (below the regulation limit for groundwater, equal to $0.18 \mathrm{mg} / \mathrm{l}$ ) and $5 \mathrm{mg} / \mathrm{l}$ (corresponding to a removal efficiency between 99 and 60\%). The removal increase was probably due to the change in the environmental conditions in terms of $\mathrm{pH}$, as presented in fig. 4 for port 1 . The best performance occurred for slightly alkaline $\mathrm{pH}$, ranging between 8 and 8.8 , confirming the results previously obtained in the batch tests. The same behaviour was observed in the other sampling ports, not presented here. 


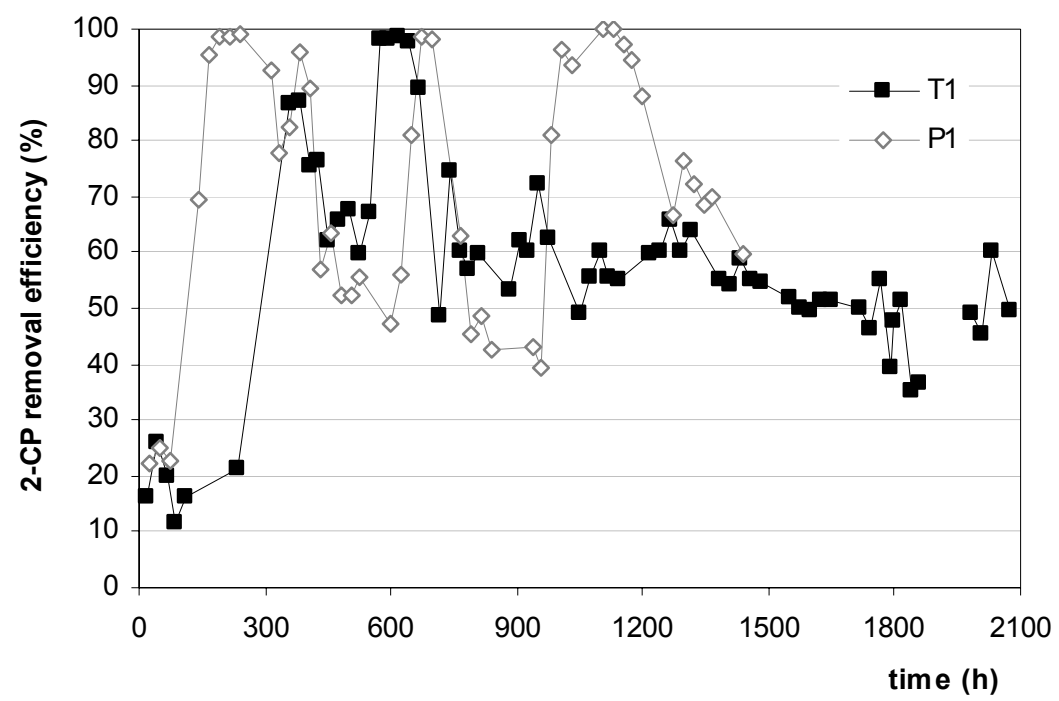

Figure 3: $\quad$ 2-CP removal efficiency time-profile for columns P1 and T1.

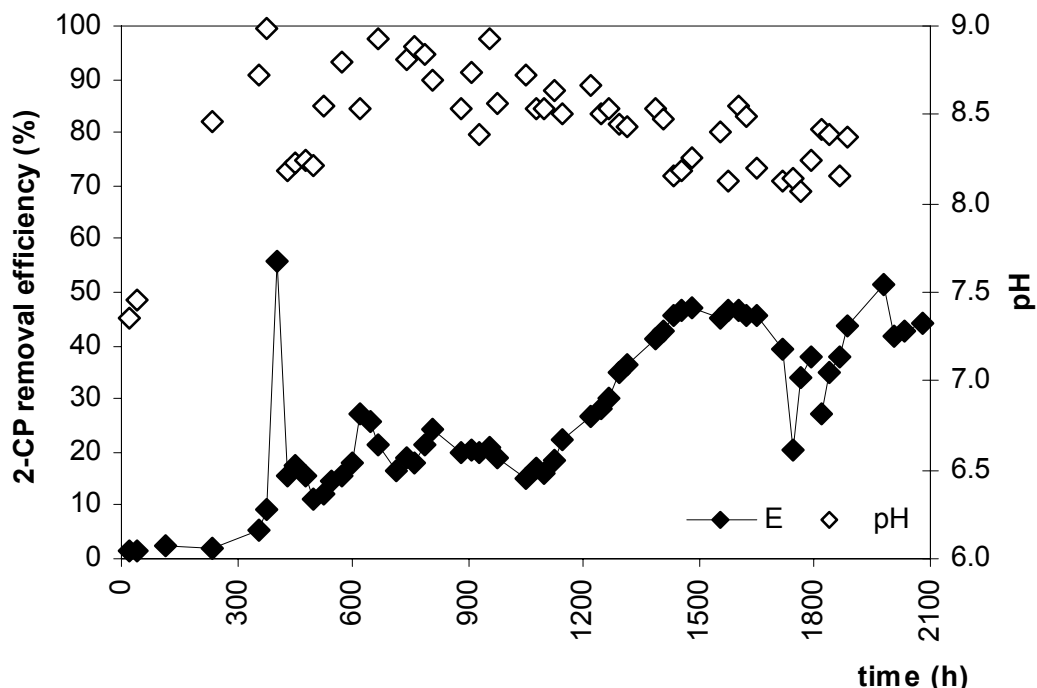

Figure 4: $\quad$ Removal efficiency and $\mathrm{pH}$ time-profiles at port 1 (column T1).

The efficiency of the column P1 decreased periodically, due to air intrusion in the column: air limiting the contact between the reactive medium and the contaminated solution, especially at the top of the column where more air was present, preventing 2-CP removal in the last few centimetres. In fact, the first three sampling ports maintained almost the same performances during the entire 
experimental activity. In these phases the overall removal efficiency was always lower than $50 \%$. The re-establishment of good performances (with efficiencies near 100\%) was obtained initially (on day 25) through the purge of the air present in the column, and then (on day 40) through a replacement of the feeding bag and of the gastight sampling ports, in order to avoid definitively further loss in performance. The 2-CP concentrations under the optimal operating conditions (in terms of $\mathrm{pH}$ ) ranged between $40 \mu \mathrm{g} / \mathrm{l}$ (the regulation limit for groundwater is $180 \mu \mathrm{g} / \mathrm{l})$ and $1.7 \mu \mathrm{g} / \mathrm{l}$. In the last 10 days the removal decreased to $60-70 \%$, probably due to the exhaustion of the material and to the progressive saturation of the active sites, since no air intrusion occurred.

In the case of column $\mathrm{P} 1$ the $\mathrm{pH}$ remained in the optimal range for the adsorption process during the entire experimental period; thus the efficiency variation was influenced mainly by the air intrusion rather than by $\mathrm{pH}$.

As far as the columns T2 and P2 are concerned (initial 2-CP concentration equal to $37 \mathrm{mg} / \mathrm{l}$ ), the overall removal efficiency obtained is presented in fig. 5; it was never higher than $60 \%$ with a mean value equal to about $50 \%$ during the entire experimental activity for both the columns. Such values are comparable to those obtained in $\mathrm{T} 1$ and $\mathrm{P} 1$ at the end of the monitoring period when a progressive saturation of the adsorption sites occurred. The worsening in the reactive media performances with respect to $\mathrm{T} 1$ and $\mathrm{P} 1$ was probably due to the higher 2-CP concentration in the inlet.

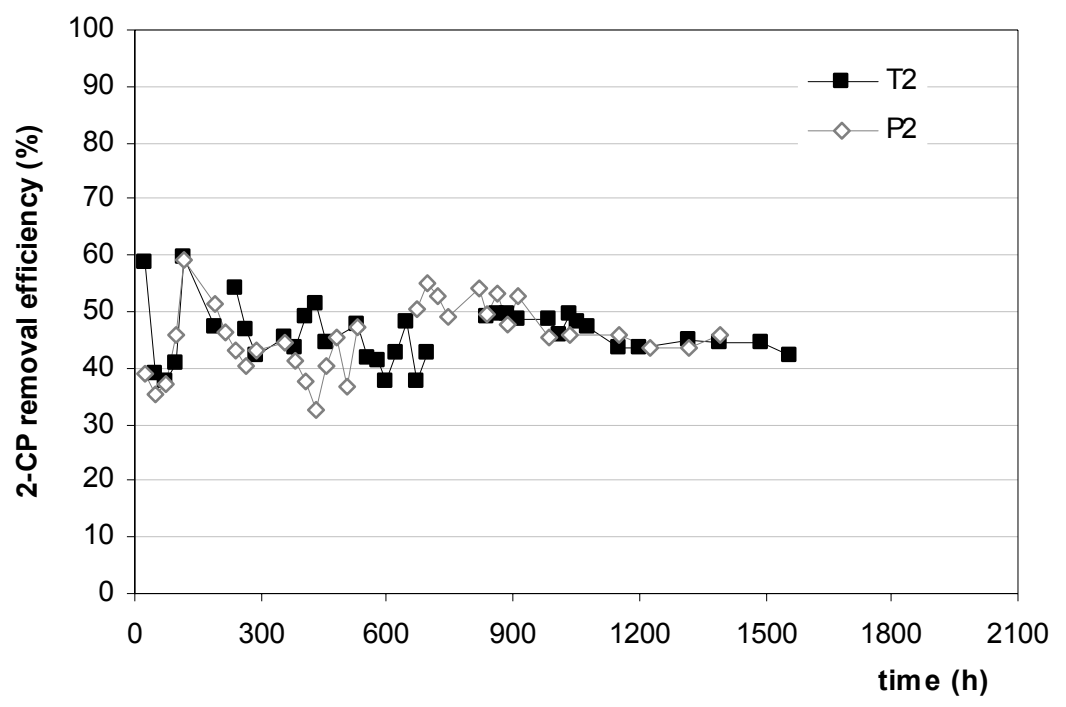

Figure 5: $\quad$ 2-CP removal efficiency time-profile for columns P2 and T2.

The removal efficiency did not vary significantly over time, with values always near the mean value. Such behaviour was probably due to the fact that $\mathrm{pH}$ assumed values almost constant in all the sampling ports, as shown in fig. 6 in correspondence to port 1 in column T2. 


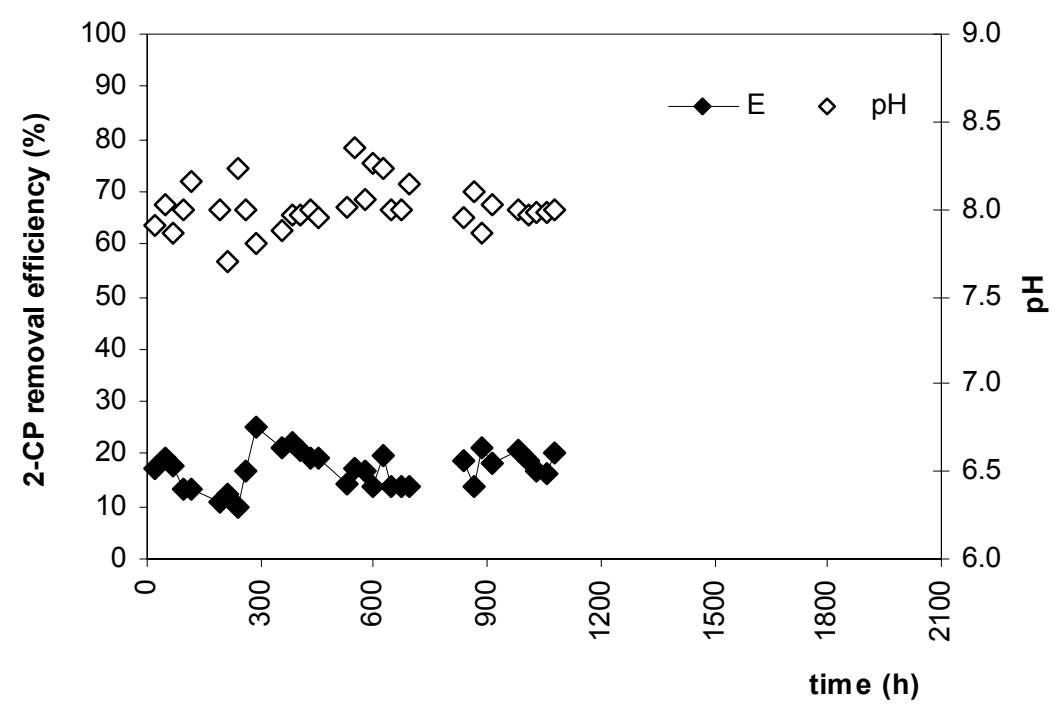

Figure 6: Removal efficiency and $\mathrm{pH}$ time-profiles at port 1 (column T2).

The 2-CP half-life $\left(\mathrm{t}_{1 / 2}\right)$ in the columns, defined as the time required for 2-CP to be reduced to half of its initial concentration, was calculated daily by using the 2-CP residual values in each sampling port of columns P1, T1, P2 and T2. To such an aim a first order reaction (exponential decay) describing the 2-CP decrease was used, with correlation coefficients higher than 0.9. In the phases characterized by significant removal efficiencies $(>80 \%), \mathrm{t}_{1 / 2}$ varied between:

- $\quad 4$ and $18 \mathrm{~h}$ for column T1 (mean value $8.6 \mathrm{~h}$, corresponding to the first 30 $\mathrm{cm}$ of the column);

- $\quad 3.2$ and $10 \mathrm{~h}$ for column P1 (mean value $5.9 \mathrm{~h}$, corresponding to the first 10 $\mathrm{cm}$ of the column).

Table 2 presents the mean half-life for all the columns in different operating conditions in terms of removal efficiencies; the materials presented similar $t_{1 / 2}$ values, depending on the initial 2-CP adopted: the higher the initial 2-CP concentration, the slower the removal kinetic. Pozzolana generally showed a more rapid removal kinetic.

Table 2: $\quad$ Mean half-life (d) corresponding to different removal efficiency for the columns.

\begin{tabular}{|l|c|c|c|}
\hline & \multicolumn{3}{|c|}{ Removal efficiency } \\
\hline column & $40-55 \%$ & $55-80 \%$ & $>80 \%$ \\
\hline T1 & 1.21 & 0.95 & 0.35 \\
\hline P1 & 1.24 & 0.79 & 0.25 \\
\hline T2 & 2.70 & - & - \\
\hline P2 & 2.59 & - & - \\
\hline
\end{tabular}




\section{Conclusions}

The results obtained confirmed that natural zeolitized materials, such as Italian native tuff and pozzolana, can be successfully used as reactive media for in situ treatment of 2-CP contaminated groundwater.

In particular, the best performances were proven to occur at moderately alkaline $\mathrm{pH}$. The behaviour of the two materials was quite similar, even if pozzolana showed a little faster removal kinetic.

Further tests are still being carried out in order to fully understand the mechanisms and the processes involved in 2-CP removal; in fact, the presence of free chlorides and of low concentrations of cathecol in the outlet suggested that along with adsorption, partial 2-CP degradation also occurred, catalyzed by the reactive media.

\section{References}

[1] Kastanek F., Meleterova Y., Kastanek P., Rott J., Jiricny V., Jiratova K., Complex treatment of wastewater and groundwater contaminated by halogenated organic compounds. Desalination, 211, pp. 261-271, 2007.

[2] Zilouei H., Guieysse B., Mattiasson B., Biological degradation of chlorophenols in packed-bed bioreactors using mixed bacterial consortia. Process Biochemistry, 41(5), pp. 1083-1089, 2006.

[3] Choi J., Kim Y., Choi S. J., Reductive dechlorination and biodegradation of 2,4,6-trichlorophenol using sequential permeable reactive barriers: laboratory studies. Chemosphere, 67(8), pp. 1551-1557, 2007

[4] Perrich J.R., Activated Carbon Adsorption for Wastewater Treatment. CRC Press, Boca Raton, FL, 1990.

[5] Calace N., Nardi E., Petronio B.M., Pietroletti M., Adsorption of phenols by papermill sludges. Environmental Pollution, 118, pp. 315-319, 2002.

[6] Banat F.A., Al-Bashir B., Al-Asheh S., Hayajneh O., Adsorption of phenol by bentonite. Environmental Pollution, 18, pp. 391-398, 2000.

[7] Yousef R.I., Tutunji M.F., G.A.W. Derwish, Musleh S.M., Chemical and structural properties of Jordanian Zeolitic Tuffs and their admixtures with urea and thiourea: potential scavengers for phenolics in aqueous medium. Journal of Colloid and Interface Science, 216, pp. 348-359, 1999.

[8] Syamsiah S., Hadi I.S., Adsorption cycles and effect of microbial population on phenol removal using natural zeolit. Separation and Purification Technology, 34, pp. 125-133, 2004.

[9] UNI, UNI-EN 12457-2:2004 Characterisation of waste, leaching: Compliance test for leaching of granular waste materials and sludge - Part 2: one stage batch test at a liquid to solid ratio of $10 \mathrm{l} / \mathrm{kg}$ with particle size below $4 \mathrm{~mm}$ (without o with size reduction), 2004.

[10] APHA, AWWA, WEF, Standard methods for the examination of water and wastewater, XX Edition. APHA, Washington, 2006. 